\title{
An Empirical Study on Correlation between Second Language Writing Anxiety and CET-4 Writing Score
}

\author{
Yu Yang \\ Jilin Agricultural University \\ Changchun, China
}

\begin{abstract}
The present study investigated the general situation of university students' second language writing anxiety and its influence on CET-4 writing score by taking 150 non English major students in Jilin Agricultural University as the research subjects. Second Language Writing Anxiety Inventory (SLWAI) developed by Cheng(2004) was adopted in this study. The result indicates that English writing anxiety exists among non-English major undergraduates; Avoidance behavior is the major source of writing anxiety; the students' writing anxiety and writing performance both changed significantly after writing practice and tests; a negative correlation exists between writing anxiety and English writing achievement. Suggestions on college English teaching of writing were discussed subsequently. The study will be helpful for both English teachers and learners to adopt effective strategies to ease anxiety and reduce the negative impact of anxiety on English writing.
\end{abstract}

Keywords—second language writing anxiety; CET-4 writing score

\section{INTRODUCTION}

Second language anxiety (SLA for short) is an essential factor affecting the second language learning. "It is always associated with negative feelings, such as frustration, disconfidence, apprehension, or hesitance.(Yang yang, 2009)" According to Zhou(2009), SLA is manifested in listening, speaking, reading, and writing and testing, of which, writing anxiety is a major branch. "Writing anxiety is more than psychological tension, but the intense anxiety or fear (Scovel, T, 1978)". "Second language writing anxiety is a kind of special anxiety which is particularly connected with the output process of second language writing. (Cheng, 1999)" The present study investigates the relationship between writing anxiety and CET-4 writing score among Chinese non-English majors. Thus, the research questions are:

(1) What is the degree of English writing anxiety of Chinese college non-English major students?

(2) What is the correlation between writing anxiety and CET-4 writing score?

Pedagogically, this study may provide supports for instructors and learners to be conscious of their writing anxiety and take reasonable strategies to overcome it and thus improve their writing performance.

\section{LITERATURE REVIEW}

\section{A. Definition of writing anxiety}

The concept "writing anxiety" was first proposed by Daly $\&$ Miller in 1975. They advocated writing anxiety as "a situation and subject-specific individual difference that is concerned with a person's general tendency to approach or avoid writing accompanied by some amount of evaluation.(Daly \& Miller, 1975)" According to Daly and Miller, Writing anxiety is to experience a high degree of anxiety in the process of writing, which leads to the avoidance of conflict. Writing anxiety can be reflected in people's behavior and attitudes, and it can also be reflected in writing performance. After Daly -Miller's investigation, writing anxiety aroused researchers' interest in the relationship between writing anxiety and writing achievement. In order to standardize the research tool, Daly and Miller developed the Writing Apprehension Test (WAT), which has been used so far.

\section{B. Previous studies on writing anxiety}

Since the term writing anxiety has been proposed, researchers have focused their eyes on the study of writing anxiety from different perspectives. "Generally speaking, studies fall on three aspects: causes and factors of writing anxiety; the connection between anxiety and performance of writing, and the ways to ease writing anxiety. (Guo Shixiang, 2016)" The representatives are Daly \& Miller who suggest that writing anxiety is developed through students' traumatic past experiences in writing, lower expectations, negative responses from teachers and lack of writing competence; Cheng (2004) who has investigated 105 English majors of National Taiwan Normal University and finds that confidence could be the cause of English writing anxiety. Powell (1984) has investigated 350 undergraduates to examine the relation between level of writing apprehension and writing performance. The writing apprehension questionnaire has investigated in composition classes and the writing test has been carried out at the end of the semester. The study reveals that highly anxious learners are likely to get low grades in writing courses than the less anxious ones. Xue Beibei (2009) has studied the strategies to ease anxiety: adjusting the teaching method, creating a relatively relaxed class atmosphere and improving the evaluation on English writing. 
Few scholars have investigated the relationship between writing anxiety and achievement in CET-4. The purpose of this study is to investigate whether English writing anxiety of non English major students influences the CET-4 writing achievement and propose appropriate teaching suggestions to improve students' English writing anxiety. The research is based on Daly \&Miller (1975) writing anxiety test scale and Cheng's (2004) second language writing anxiety scale.

\section{C. $C E T-4$}

College English Test Band 4, namely CET-4, is a nationwide standardized examination of single subject. The major participants of the examination are undergraduates or postgraduates of Chinese non-English majors. The English proficiency of non English major students could be proved objectively and accurately in the test. Writing scores of CET-4 is a reliable standard to measure students' writing ability.

\section{RESEARCH DESIGN}

\section{A. Participants}

In this study, 154 non English major students were selected from three paralleled classes at Jilin Agricultural University. The students, including 65 boys and 85 girls, are all freshmen majoring in agronomy and resources, whose average age is 19. They all have six years of English learning experience and none of them have ever been abroad to study. The participants were sampled and tested for a period of two semesters. The questionnaire and tests for the subjects were finally fully recovered. Data collected are valid except from 4 students failing to complete the questionnaires or the writing test.

\section{B. Tools}

\section{1) Second Language Writing Anxiety Inventory (SLWAI)}

SLWAI (Y S Cheng, 2004) is adopted in the present study to measure the degree to which students feel anxious in English writing. More specifically, Cheng (2004) classified the three factors of writing anxiety as: "(1) Somatic Anxiety, defined by items relating to increased physiological arousal; (2) Avoidance Behavior, comprised of items indicative of avoidance behavior; and (3) Cognitive Anxiety, a subjective component that deals with perception of arousal and, in particular, worry or fear of negative evaluation". Cheng's questionnaire contains 22 items which are in the Likert 5 scale form. There are 5 options from "totally disagree" (1 points) to "strongly agree" (5 points). Of the 22 items, 7 questions are scored reversely in the statistical scores. The total score for all 22 items is anxiety value. The higher the score, the deeper the anxiety, and vice versa. A higher score means the participants experience the higher level of writing anxiety, to be detailed, a higher degree of avoidance tendency, or worry associated with second language writing. Among them, higher than 65 is "high anxiety", less than 50 is "mild anxiety", the other is "moderate anxiety"". In this study, personal information was added to the questionnaire while designing, such as gender, age, major, CET-4 writing score, and self-evaluation of English writing ability. In order to ensure the authenticity and reliability of the study, the subjects were informed before the investigation that the findings were only used in English teaching and research and would not have any influence on their English scores of the current semester.

\section{2) Writing test measurement}

The study selected valid scores of four writing tests, of which two tests are the National College English Test Band 4 held in June and December of the year 2016 respectively, and the other two tests are the final examination of College English held in July and January in Jilin Agricultural University. The form and content of all the writing tests are in agreement with CET-4 writing test. The students are required to complete in 30 minutes. Three experienced college English teachers graded the composition with the CET-4 writing scoring standard (15 point system scoring method). The correlation coefficient of the reviewers was $0.712,0.723$ and 0.730 respectively. The final writing scores of the subjects were the average of scores which three teachers submitted.

\section{3) Data collecting}

150 participants took part in the CET -4 and final examinations of two semesters in July 2016 and January 2017 in Jilin Agricultural University. Before each test, the students participated in the questionnaire which was tested by the English teacher in class and recovered on the spot. The participants were not disturbed while answering the questionnaire and left plenty of time to finish. The questionnaire and four test scores were input into the software SPSS and then processed and analyzed. The overall scores and level of the English writing anxiety were obtained after analyzing. Then, the Pearson correlation coefficient was calculated to measure the influence of the English writing anxiety on CET-4 writing scores.

\section{Results analysis and discussion}

\section{1) General situation of English Writing Anxiety}

Firstly, the general situation and degree of English writing anxiety among the subjects were statistically analyzed. Table 1 shows that non English major students in Jilin Agricultural University commonly experienced medium or higher levels of writing anxiety during four tests, of which students experienced the highest degree of writing anxiety in June of 2015 with the average anxiety value up to 69.56 and the highest anxiety score of 101 . The result is related to students' participating in the CET- 4 writing test for the first time after entering the university. Writing anxiety decreased gradually three times after the first test with the degree of writing anxiety being reduced to moderate in December 2016 and January 2017 for that plenty of writing training had been done during that period of time. It can be concluded that the degree of writing anxiety is quite related to writing practice frequency. As shown in table 1, the degree of writing anxiety before the CET-4 writing test is higher than that before the final examination, which indicates that the students attach more importance to and are more anxious about the CET- 4 writing test. 
TABLE I. Statistics OF WRITING ANXIETY BEFORE FOUR TESTS

\begin{tabular}{|c|c|c|c|c|}
\hline $\begin{array}{c}\text { Comprehensive } \\
\text { anxiety }\end{array}$ & Number & Minimum & Maximum & Mean \\
\hline 2016.6 & 150 & 48 & 101 & 69.56 \\
\hline 2016.7 & 150 & 42 & 92 & 65.43 \\
\hline 2016.12 & 150 & 38 & 87 & 62.12 \\
\hline 2017.1 & 150 & 34 & 82 & 57.75 \\
\hline
\end{tabular}

Fig. 1 indicates that for the four tests avoidance behavior varies markedly, while cognitive anxiety is in minimal change and somatic anxiety almost remains unchanged at all. The decline in avoidance behavior led to a obvious weakness in anxiety degree. The result shows that avoidance behavior is the major source of writing anxiety. Students try to avoid the CET-4 writing test deliberately. Being afraid of failing in writing tests leads to writing anxiety.

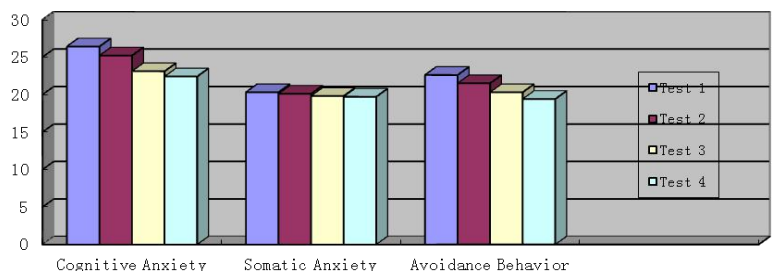

Fig. 1. Descriptive Statistics of Three Categories of Anxiety
2) Correlation between English writing anxiety and writing score in four tests

Table two shows that a negative correlation exists between English writing anxiety and writing scores in CET-4. Before the test in June 2016, the writing anxiety degree was highest with anxiety value up to 69.56 , and ultimately the average of writing score is lowest of the four tests. In January 2017, the anxiety value dropped a lot and then the average writing score was the highest. This shows that the level of writing anxiety directly affects the students' writing level and ability, thus affecting writing achievement in CET-4. The writing score distribution also reflects that two national level CET-4 scores were significantly less than the final exam scores, which indicates students bear higher pressure in CET-4. Therefore, the anxiety value is higher resulting in relative lower scores. This result also shows that the writing is a kind of output activity influenced by pressure significantly. Even though some students are superior in writing skills, they also feel medium or high degree of anxiety in CET-4, thus affecting the performance.

TABLE II. CORRELATION BETWEEN Writing ANXIETY AND SCORES IN FOUR TESTS

\begin{tabular}{|c|c|c|c|c|c|}
\hline \multicolumn{2}{|c|}{} & Total Anxiety & Cognitive Anxiety & $\begin{array}{l}\text { Somatic } \\
\text { Anxiety }\end{array}$ & Avoidance Behavior \\
\hline \multirow{2}{*}{ Test 1} & Pearson Correlation & $-.501^{* *}$ & $-.509^{* *}$ & $-.397^{* *}$ & $-.531^{* *}$ \\
\cline { 2 - 6 } & Sig.(2-tailed) & .003 & .001 & .005 & .000 \\
\hline \multirow{2}{*}{ Test 2} & Pearson Correlation & $-.523^{* *}$ & $-.567^{* *}$ & $-.401^{* *}$ & $-.597^{* *}$ \\
\cline { 2 - 6 } & Sig.(2-tailed) & .007 & .003 & .009 & .000 \\
\hline \multirow{2}{*}{ Test 3 } & Pearson Correlation & $-.548^{* *}$ & $-.565^{* *}$ & $-.426^{* *}$ & $-.603^{* *}$ \\
\cline { 2 - 6 } & Sig.(2-tailed) & .001 & .002 & .003 & .001 \\
\hline \multirow{2}{*}{ Test 4 } & Pearson Correlation & $-.543^{* *}$ & $-.571^{* *}$ & $-.388^{* *}$ & $-.621^{* *}$ \\
\cline { 2 - 6 } & Sig.(2-tailed) & .003 & .002 & .004 & .002 \\
\hline
\end{tabular}

**.Correlation is significant at the 0.01 level (2-tailed)

In addition, table two shows that the negative correlation between avoidance behavior and writing performance is the strongest, followed by cognitive anxiety, and somatic anxiety. It indicates that students are reluctant to take part in the CET-4 writing test and have strong resistance and avoidance of the behavior, which leads to the rise of anxiety value and decline in writing achievement. In addition, students' lack of confidence in writing and lower self-evaluation of writing ability also deepen the students' cognitive anxiety degree, thus making a negative effect on the writing achievement.

\section{3) Pedagogical implications}

The findings show that English writing anxiety has seriously hindered the improvement of students' CET-4 writing achievement and writing proficiency. Therefore, college English teachers should diversify their teaching methods and adjust evaluation methods to alleviate students' writing anxiety. Writing class should be students-centered and teachers should not dominate the whole writing process. The essential task of teachers is to assist students in conceiving and discussing. Students actively participate in the writing process through various forms of class such as on-line class, micro class and flipped class with the lower degree of cognitive anxiety about writing.
Meanwhile, the somatic anxiety of the students in face of new writing tasks will be greatly reduced through the discussion with the teacher. In addition, the method of writing evaluation can be diversified. Peer assessment among students can lower students' fear level of writing scores and reduce students' anxiety and avoidance behavior for negative evaluation. Through peer review, students recognize that language errors may be common, thus alleviating writing anxiety and setting up self-confidence in English writing.

\section{CONCLUSION}

This study is an explorative empirical study of college teaching in English writing among Jilin Agricultural University students. The sample in the present study is merely collected from only one university and the limited number of majors so that it may be difficult to apply the findings to all the learners in China and other countries. The experiment cycle is only one academic year. Although the interference of irrelevant variables has been controlled as much as possible during the experiment, some uncontrollable disturbance variables still exist. It is found that there is a middle or higher degree of English writing anxiety among non English major students in Jilin Agricultural University, and that the level of writing anxiety is negatively related to the writing 
achievement. English writing anxiety has hindered the improvement of students' CET-4 writing achievement and writing proficiency. The study also found that avoidance behavior and cognitive anxiety were the main sources of students' writing anxiety and had a negative impact on students' English proficiency. Therefore, college teachers should understand and pay more attention to students' writing anxiety in English teaching and help students build selfconfidence, stimulate interest in learning, and lower the negative impact of writing anxiety for students through appropriate teaching methods and strategies so as to improve students' English writing ability and improve the writing performance in CET-4. Accordingly, the further researches can extend the research subject to more students from different majors. And a qualitative analysis can be applied to the future study to investigate students' thinking process in writing. Furthermore, the relationship between writing anxiety and other index of writing performance can be examined in the future researches.

\section{REFERENCES}

[1] Cheng Y . A measure of second language writing anxiety: Scale development and preliminary validation [J]. Journal of Second Language Writing, 2004, (4) : $313-335$.

[2] Cheng Y, Horwitz E K \& Schallert D R. Language anxiety: Differentiating writing and speaking components [J]. Language Learning, 1999, (3): 417- 446.

[3] Daly, J.A. \& Miller, M.D. The empirical development of an instrument to measure writing apprehension [J]. Research in the Teaching of English. 1975, 9 (3): 242-249.

[4] Guo Shi-xiang. An Empirical Study on the Influence of AAWP Teaching Model on English Majors' Writing Anxiety. [J]. Journal of PLA University of Foreign Languages. 2016,(7): 111-118.

[5] Powell, B .1984. A comparision of students' attitude and success writing. [J]. Journal of Negro Education, 53:114-223.

[6] Scovel, T. The Effect of Affect on Foreign Language Learning: a review of the anxiety research. [J]. Language Learning, 1978, (28): 129-42.

[7] Xue Beibei. Analysis of causes of English writing and Countermeasures. [J]. Journal of Language and Literature Studies. 2009.5.

[8] Zhou Xiaoli. Causes of Listening Anxiety in English Class and the Relationship with Listening Scores in CET-4. [J]. Journal of Chongqing Jiaotong University. 2009,2.

[9] Yang Yang. The classroom anxiety: A Study of the College Students' Writing Performances and Strategies Uses. [D]. 2009,6. 